\title{
Evaluación de la estructura poblacional arbórea del manglar en el Parque Histórico de Guayaquil
}

\author{
Xavier Mendoza Delgado / Natalia Molina Moreira
}

\section{Resumen}

El Parque Histórico Guayaquil (PHG) mantiene un remanente de bosque de manglar en la zona de vida silvestre y restaurado desde el año 2000 por la Fundación Ecológica Rescate Jambelí; con un diagnóstico sus técnicos establecieron procesos para la zonación del manglar, hicieron viveros en sitio de: Rhizophora harrisonii, Rhizophora mangle, Laguncularia racemosa, Avicennia germinans y Conocarpus erectus, etiquetaron 296 mangles originales del PHG de Rhizophora spp., reportaron plagas del manglar y elaboraron un Plan de Manejo Ambiental (PMA). Catorce años después esta investigación actualizó el registro de datos según metodologías aplicadas en los años 2000, 2002, 2005, 2006 y 2007, para evaluar la estructura del manglar del PHG, obteniendo como resultado que se ha alterado la zonación del manglar: A. germinan y L. racemosa han perdido más del 95\% de sus individuos, debido a la falta de ejecución del PMA; por lo que se propone controlar y auditar la ejecución del mismo para recuperar el manglar del PHG.

\section{Palabras clave:}

Manglar, zonación, restauración, plan de manejo, estructura.

\begin{abstract}
The Parque Histórico Guayaquil maintains a mangrove forest in its Wild Life Area which has been rehabilitated since 2000 by the Fundación Ecológica Rescate Jambelí. The diagnosis given by the technicians established processes for the division into mangrove areas. Tree nurseries were created for Rhizophora harrisonii, Rhizophora mangle, Laguncularia racemosa, Avicennia germinans and Conocarpus erectus and 296 original mangroves of Rhizophora spp. were labeled, mangrove plagues were also reported and a management plan was presented. Fourteen years later, this research updated a new data information according to methodologies applied in the years 2000,2002, 2005, 2006 and 2007 to assess the structure of the PHG's mangrove. The finding is that there has been an alteration in the zonation of the mangrove: A. germinant and L. racemosa have lost more than $95 \%$ of its units due to the lack of execution or accomplishment of the management plan. It is recommended to monitor and audit the execution of the Plan in order to restore the mangrove forest of the PHG.
\end{abstract}

\section{Keywords:}

Mangrove, zoning, rehabilitation, management plan, structure. 


\section{Introducción}

Los ecosistemas naturales que se encuentran dentro de las áreas urbanas deberían ser los más protegidos, aprovechando no solo el paisajismo, sino los servicios ambientales que estos otorgan. En este artículo se tratará exclusivamente del bosque de manglar del PHG. Los manglares son humedales tropicales de aguas saladas y estuarinas que se establecen en zonas intermareales, son asociaciones anfibias de plantas leñosas y arbustivas que reciben nutrientes y energía tanto del suelo como del mar (Velverde \& Pérez, 2012, pág 61).

En Ecuador existen ocho especies de mangle; cinco están distribuidas en la provincia del Guayas; estas son: $R$. harrisonii, $R$. mangle, A. germinans, L. racemosa y C. erectus, como lo manifiesta Molina, Zambrano, Arias y Vivas (2000). Valverde y Pérez (2012, pág.61) mencionan que según el Centro de Levantamientos Integrados de Recursos Naturales por Sensores Remotos (CLIRSEN) en 1995 en Guayas-Santa Elena se registró 103.730,10 hectáreas de manglar, cifra que representa una pérdida de alrededor del $17 \%$ del manglar en un período de 26 años ya que según Valverde (1998, pág. 19) en 1969 registró 125.523 hectáreas.

Los manglares dentro del PHG tienen dos orígenes; un grupo fue hallado dentro del lugar en estado natural; mientras que la otra parte fue sembrada para restaurar este ecosistema, considerando la zonación natural de los manglares del Golfo de Guayaquil (Molina, et al., 2000); en el caso de las especies de Rhizophora spp., se reforestó a través de propágulos, mientras que las demás especies se sembraron mediante semillas.

Al primer grupo se le asignaron placas con un número para su identificación y así poder llevar un registro adecuado (Molina \& Molina, 2005). Se han realizado conteos de los mangles originales en los años 2000 , 2002, 2005, 2007 e inventarios en los años 2002 y 2007, además se han realizado siembras en el 2000 y 2005; por lo que es necesario actualizar y comparar la información para conocer el crecimiento de los mangles del género Rhizophora y la estructura del bosque de manglar.

El PHG se caracteriza por recrear los bosques existentes en la región costera del país, además de representar la cultura rural y arquitectónica a comienzos del siglo XX. La Zona de Vida Silvestre (ZVS) del PHG destina $17000 \mathrm{~m} 2$ a los manglares (Molina \& Molina, 2005).

Como es mencionado por Reese (2007) la regeneración del mangle es un indicador del estado del bosque. Por este motivo se realiza la investigación, teniendo en cuenta los cambios que se pudieran efectuar en la restauración de un ecosistema; en este caso el del manglar, Bodero \& Robadue (1995) indican que la reforestación con mangles puede no tener éxito debido al mal manejo que se le da al ecosistema. El manglar tiene servicios ambientales importantes que pudieran beneficiar a la sociedad pero son el resultado de un estado saludable y del buen manejo que se realice.

La investigación tiene como propósitos: actualizar el inventario de los mangles originales del $\mathrm{PHG}$, actualizar el inventario de todas las especies de mangle sembradas desde el año 2000 y proponer nuevos lineamientos en el plan de manejo ambiental (PMA) elaborado por Molina, Baquerizo, Orrantia, Fernández-Madrid, Pesántez y Pesántez (2006), para mantener la estructura del manglar.

Estos objetivos permitirán establecer una comparación del estado del manglar del PHG desde el año 2000 al 2014, para contribuir a la conservación de la estructura del ecosistema del manglar que se restauró según la zonación presente en el Golfo de Guayaquil desde hace 14 años en el PHG. 


\section{Fundamentación Teórica}

Los manglares son de los ecosistemas más estudiados y se encuentran en las regiones tropicales y subtropicales del planeta, como lo indican Infante, Moreno y Madero (2014) en su referencia de Spalding et al. (2010). En los manglares "las plantas dominantes son los mangles, que incluyen ocho familias y doce géneros" (Smith \& Smith, 2001: 583). El Centro de Levantamientos Integrados de Recursos Naturales por Sensores Remotos (CLIRSEN, 2007), argumenta que la principal característica de los manglares es que crecen en ambientes salinos, con una marcada zonificación, de acuerdo al nivel de salinidad del lugar. Francisco, Díaz, Romano y Sánchez (2009) en la referencia que realizan de Tomlinson (1986), enfatizan que ciertas especies de mangle, para poder tolerar la salinidad, tienen mecanismos para excretar las sales en exceso.

En el transcurso de los años los bosques de manglar a nivel mundial han sufrido la disminución de su extensión y de la abundancia de sus especies; entre las causas más importantes se encuentran: el incremento de la urbanización por aumento de la población (la mayor parte de las comunidades se sitúa en franjas costeras o cerca de cuerpos de agua), la utilización de las tierras para cultivos agrícolas (Bolívar, 2014: 2), además del establecimiento de piscinas para la crianza de peces y camarones; las que a su vez generan un problema mayor de contaminación, ya que sus descargas a los esteros o ríos generan un exceso de nutrientes, también llamado eutrofización (Moroyoqui et al., 2012: 334).

"Los manglares son zonas vulnerables y de gran importancia biológica, social y económica" (Zamora \& Cortés, 2009: 474); lo importante de los bosques de manglar, según es indicado por Suman (1994), radica en varios factores; entre los que se pueden mencionar algunos en los que el ser humano se beneficia de ellos: la diversidad de especies encontradas dentro del bosque, siendo una fuente de alimento y sustento económico para los habitantes de áreas aledañas, Cedeño \& Bravo (2012) concuerdan que los principales recursos extraídos del manglar son los cangrejos, conchas, ostiones, mejillones, entre otros. Además la Universidad de Wisconsin (1975), en su libro "El hombre en el medio ambiente vivo", resalta que la mayor parte de las especies pescadas por el hombre a nivel general; es decir que se incluye las que habitan en alta mar, tiene un fuerte nexo a los sistemas estuarinos entre los que se menciona el manglar; ya que en la etapa juvenil los peces se localizan en estas zonas debido a su productividad en nutrientes, lo que beneficia a su crecimiento.

El Centro de Investigaciones Universitarias de la Universidad Laica Vicente Rocafuerte (CIU, 1995) realza la importancia del manglar al ser fuente de nutrientes y de aceptación en el comercio por parte de los ciudadanos para el consumo de sus productos. Solano, Flores y Ruíz (2010) mencionan que el valor comercial calculado en cuanto a extracción de recurso pesquero, crustáceos y mariscos puede variar desde $\$ 750.00$ hasta $\$ 16,750.00$ por hectárea al año, dependiendo de la zona y su productividad. También se indica por el CIU (1995) que la hojarasca producida por el manglar beneficia con sus nutrientes el desarrollo y crecimiento de diferentes tipos de mariscos, así lo confirman Félix, Holguín, Hernández y Flores (2006) en su afirmación que la hojarasca ocupa entre $20 \%$ y $40 \%$ de lo que produce el ecosistema.

A su vez, Parra \& Restrepo (2014) establecen que los manglares sirven como barreras naturales cuando suceda un aumento del nivel del agua, generado por algún fenómeno natural, como los tsunamis; esto se debe al amortiguamiento de las mareas producido por las raíces fúlcreas de la especie Rhizophora mangle o Rhizhophora harrisonii, como lo especifica el CIU (1995). 
Por último Sanjurio \& Welsh (2005), se refieren a la importancia de los mangles como sumideros de carbono. Todo árbol necesita el dióxido de carbono para realizar su fotosíntesis; sin embargo, los bosques de mangle tienen una ventaja en este aspecto comparados con los demás tipos de bosque, durante el proceso de intercambio gaseoso que forma parte de la fotosíntesis, el carbono no es liberado o devuelto en grandes cantidades, esto se debe a que el tipo de suelo favorece al almacenamiento de carbono por su ritmo lento de descomposición. A esto se añade lo que hace mención Bolívar (2014) en cuanto a captura de carbono, los mangles junto a otros ecosistemas costeros que tienen flora, se les denomina sumideros Blue Carbon, esto se debe a que se estima que capturan más del $50 \%$ del carbono de los fondos oceánicos. Díaz, Castro y Manjarrez (2010) indican que en cuanto a la importancia biológica, esta se resume en: ofrecer protección tanto para las especies que ahí habitan, como para la costa en general, además el microclima generado en los bosques de manglar favorece el desarrollo de diferentes especies de moluscos, crustáceos, peces, especies que probablemente terminen siendo fuente de alimento para otras.

Como lo menciona Cedeño \& Bravo (2012), los bosques de manglar son de extrema importancia, ya que en ellos existe una considerable diversidad de flora y fauna; mientras que Brown et al. (1992), resaltan que los manglares junto a los demás ecosistemas costeros cumplen la función de protección contra la contaminación, producida en el interior del continente hacia las zonas que se ubican en las afueras de la costa.

\section{Distribución}

Quintana (2007) detalla que en el continente americano la extensión de los bosques de manglar cubre un área mayor a $40,000 \mathrm{~km}^{2}$. La misma autora establece que la mayoría de los individuos de mangle se encuentran en el Atlántico y el Caribe; mientras que en la costa del Océano Pacífico se distribuye en menor cantidad, esto se debe a las características y corrientes marinas que interactúan a lo largo del año; por lo que según menciona Suman (1994), el mangle se distribuye de acuerdo a su tolerancia en cuanto a temperatura.

A su vez Molina Raquel, et al. (2000) en su referencia al CLIRSEN (1999), explican que los manglares en el Ecuador se encuentran ubicados en cinco de las siete provincias de la costa del país (Esmeraldas, Manabí, Guayas, Santa Elena y El Oro) y en la región insular (Islas Galápagos), donde se pueden encontrar seis especies de mangle en una extensión aproximada de 149,556.23 hectáreas. En Esmeraldas, según los autores Odum \& Sarmiento (1997) los mangles alcanzan alturas de 45 metros. Mientras que el CIU (1995) indica que los bosques de manglar se localizan específicamente en "zonas estuarianas de los sistemas hidrográficos de los ríos Mataje-Santiago-Cayapas, Muisne, Cojimíes, Chone, Guayas, Jubones-Santa Rosa-Arenillas." Las especies mencionadas anteriormente se detallan a continuación:

- Mangle Rojo (Rizhophora mangle): Jiménez (1999) señala que esta especie se distingue por sus hojas con forma ovalada y ancha, teniendo flores que producirán propágulos con cantidades que varían de 1 a 4 unidades. La especie tiene raíces fúlcreas que le permiten fijarse al suelo pantanoso y que se las pueden confundir con troncos. Según el CIU (1995), el color de la corteza interior es muy característico, llegando a ser un color rojo intenso o rosado, parecido a la sangre del ser humano.

- Mangle Rojo (Rhizophora harrisonii): En referencia a Cevallos, Cortez y Hurtado (2010), esta especie de mangle rojo se diferencia de la 
anterior en cuanto a su inflorescencia, llegando a tener entre 5 a 32 flores, siendo más notoria que la de Rhizophora mangle.

- Mangle Blanco (Laguncularia racemosa): Como lo mencionan Agraz, Noriega, López, Flores y Jiménez (2006), esta especie es la que tiene menor resistencia a la salinidad del agua estuarina, el oleaje permite que el agua se mantenga más tiempo en donde se encuentra esta especie. Además en su estructura hay sistemas para la expulsión de sales y algunos que ayudan en el intercambio gaseoso, como las lenticelas en sus neumatóforos para capturar el oxígeno de la atmósfera. Según el CIU (1995), los individuos de esta especie pueden llegar a medir entre 8 y 15 metros de altura.

- Mangle Negro (Avicennia germinans): La especie tiene una "corteza fragmentada en placas, hoja lanceolada donde el contraste no es tan marcado, la parte interna de la corola posee una coloración amarilla" (Jiménez, 1999).

- Mangle Jelí (Conocarpus erectus): Como es mencionado por Agraz et al. (2006), esta especie de mangle se la puede observar en la parte más exterior del bosque; es decir, no está en contacto con el cuerpo de agua; sin embargo la salinidad en la que se encuentra es bastante alta. Así como en otras especies, esta tiene mecanismos para excretar sales.

Mangle piñuelo (Pelliciera rhizophorae): Según lo detallado por von Prahl (1987), el mangle piñuelo puede llegar a una altura promedio de 15 metros o más. Otra de las características que se indican es la forma del árbol, el cual tiene raíces tabloides que se asemejan a un triángulo en su base, lo que lo diferencia notablemente de las otras especies.

Como indica el CLIRSEN (2007), los manglares del Ecuador están protegidos mediante leyes que han sido decretadas desde 1986; por lo que en teoría los bosques de mangle deberían ser respetados y no deforestados.

Sin embargo como menciona Molina Raquel, et al. (2000), hasta el año 2000 el total de mangles había disminuido en un $26 \%$, a pesar de la legislación y de su importancia por sus diferentes usos y funciones ecosistémicas. Suman (1994) hace énfasis en que las prácticas que más han afectado a los bosques de manglar del país son las de agricultura, ganadería, construcción de urbanizaciones y maricultura, siendo Manabí la provincia en la que el porcentaje de pérdida de bosque ha sido mayor.

El mismo autor señala que hasta el año 1994 se registró alrededor del $12 \%$ de deforestación de manglar en la provincia del Guayas.

\section{Descripción del Área de Estudio}

Dentro de la provincia del Guayas se encuentra ubicado el PHG. El parque fue inaugurado en el año 1999, siendo encontrados en ciertas áreas árboles de la especie conocida como mangle rojo (Rizhophora spp.); por lo que se decidió plantar más individuos de ese género, además de mangles blancos, negros y jelí, para poder recrear una zonificación como se observaría en su estado natural.

En referencia a Molina Raquel, et al. (2000), los bosques de manglar estaban siendo afectados por diferentes plagas. A partir de ese momento se comenzaron a tomar medidas, que fueron recomendadas por los autores antes mencionados, para que la reforestación del parque se la realice de forma exitosa. 
El PHG está localizado en el cantón Samborondón junto al río Daule, comprende 8 hectáreas de extensión (Parque Histórico Guayaquil, 2014). Como menciona ELICONSUL (Elite Consultor Cia. Ltda., 2013), la zona se encuentra en una región donde existen dos estaciones muy marcadas, como la seca y lluviosa. También indica que el clima promedio del área es de 26 grados centígrados, teniendo como valores máximos y mínimos promedio de $30^{\circ} \mathrm{C} \mathrm{y} 23^{\circ} \mathrm{C}$, respectivamente; además la precipitación promedio anual es de 1,050 milímetros y cuenta con una humedad promedio del $74 \%$.

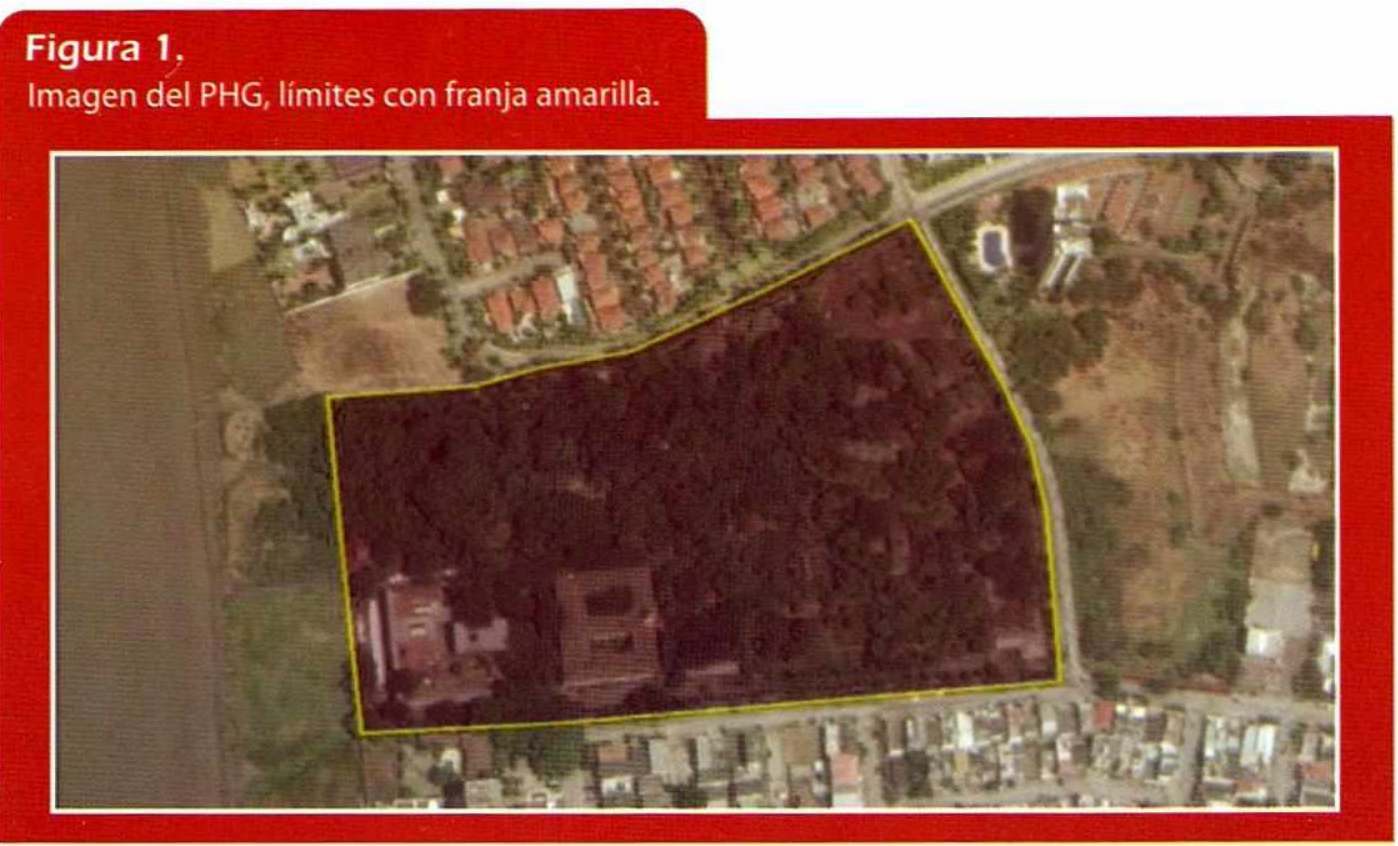

Fuente: Mendoza, X. 2014

El parque recrea los diferentes ecosistemas encontrados en la región costera del país; por lo que su composición original varió para albergar distintas especies tanto de flora como de fauna, además de una zona en la que se puede observar la arquitectura de Guayaquil de comienzos del siglo XX y las casas de la parte rural costera del Ecuador (Parque Histórico Guayaquil, 2014).

Según lo indicado por Molina \& Molina (2005), en la ZVS del PHG la especie dominante de mangle era Rhizophora spp. Sin embargo, debido a la sedimentación, la especie Avicennia germinans (mangle negro) había desaparecido antes del año 2000 y en su lugar estaban creciendo herbáceas, lo que se podía deducir como una sucesión.

Molina \& Molina (2005), detallan que se realizaron trabajos de dragado para solu- cionar el problema de la sedimentación que no permitía un desarrollo adecuado del bosque de manglar; así como podas y raleos, los cuales ayudaron al crecimiento de las diferentes especies de mangle. Se recomendó mantener constantemente los canales libres de cualquier indicio de sedimentación que pudiera afectar a los manglares del PHG.

El PHG fue construido por iniciativa del Banco Central del Ecuador; sin embargo desde el año 2012 el parque es administrado por la Empresa de Parques Públicos del Ecuador (Parque Histórico Guayaquil, 2014), dentro del PHG existen las especies de mangle: Rhizophora mangle, Rhizophora harrisonii, Avicennia germinans, Laguncularia racemosa y Conocarpus erectus (Ver Figura 2), a las que se muestreó para la elaboración del presente artículo académico. 


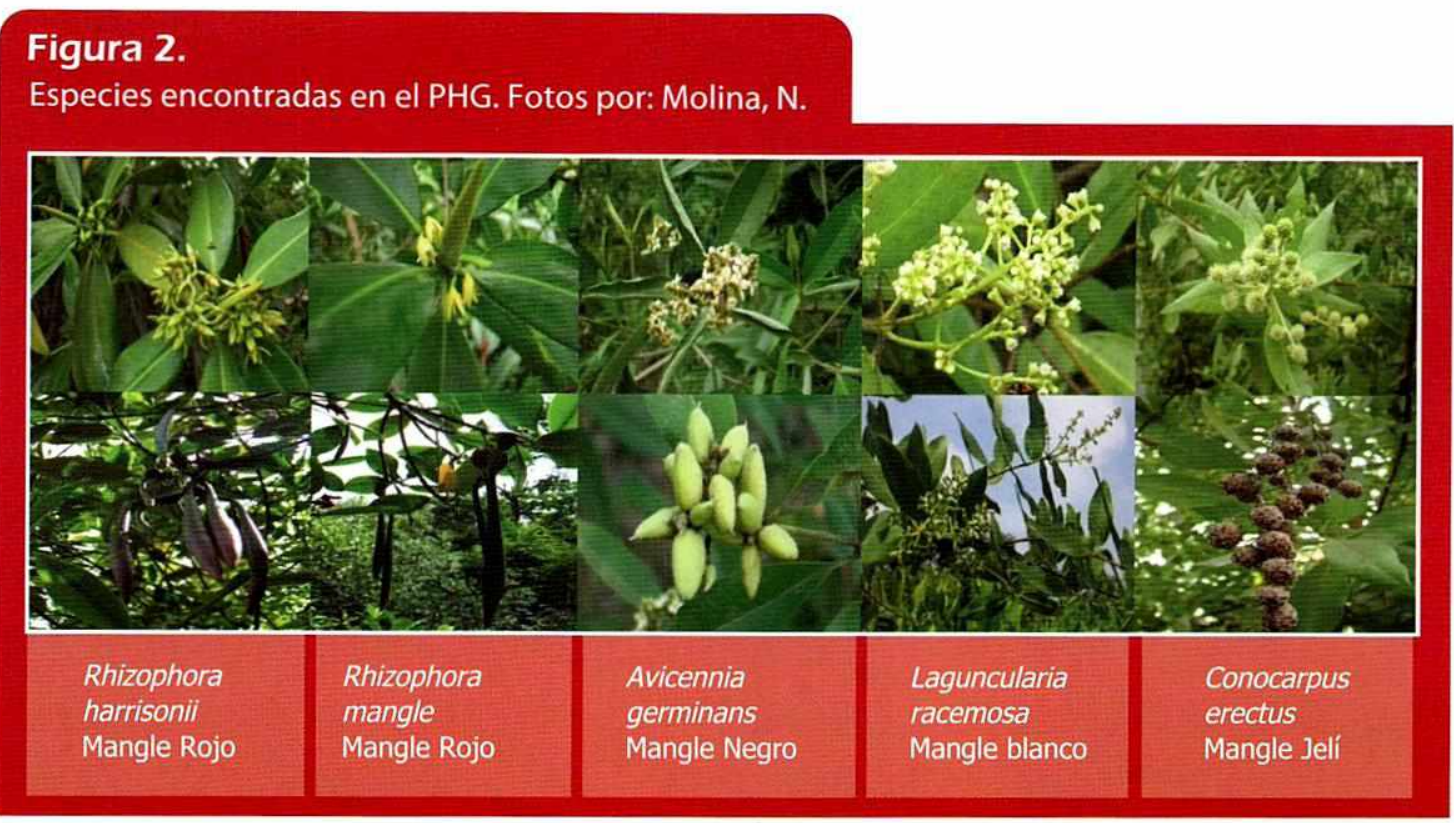

\section{Metodología}

Para la investigación descriptiva, en el trabajo de campo se utilizaron diferentes métodos para recolectar los datos requeridos. El trabajo fue dividido según los objetivos; por lo que se distribuyeron los días de muestreo de acuerdo a la disponibilidad por parte de las autoridades del PHG, teniendo en cuenta los flujos de marea y accesibilidad en las áreas a muestrear.

Para el registro de los mangles con placa (mangles rojos), en el cual se procedió a medir arriba de la placa y debajo de la placa según el método de medición realizado por Molina Raquel, et al. (2000), además se calculó la altura y el tamaño de la copa, para así según los resultados, establecer el crecimiento en los 14 años desde que los individuos fueron inventariados en el PHG. Para comparar la regeneración de mangle rojo se utilizó el mismo método de Molina Raquel, et al. (2000), se muestrearon 10 parcelas de $1 \mathrm{~m} \times 1 \mathrm{~m}$, contabilizando los propágulos anclados que estén vivos, los no anclados y los muertos o infectados por plagas.

\section{Figura 3.}

Recolección de datos - Medidas de las placas y cuadrantes.

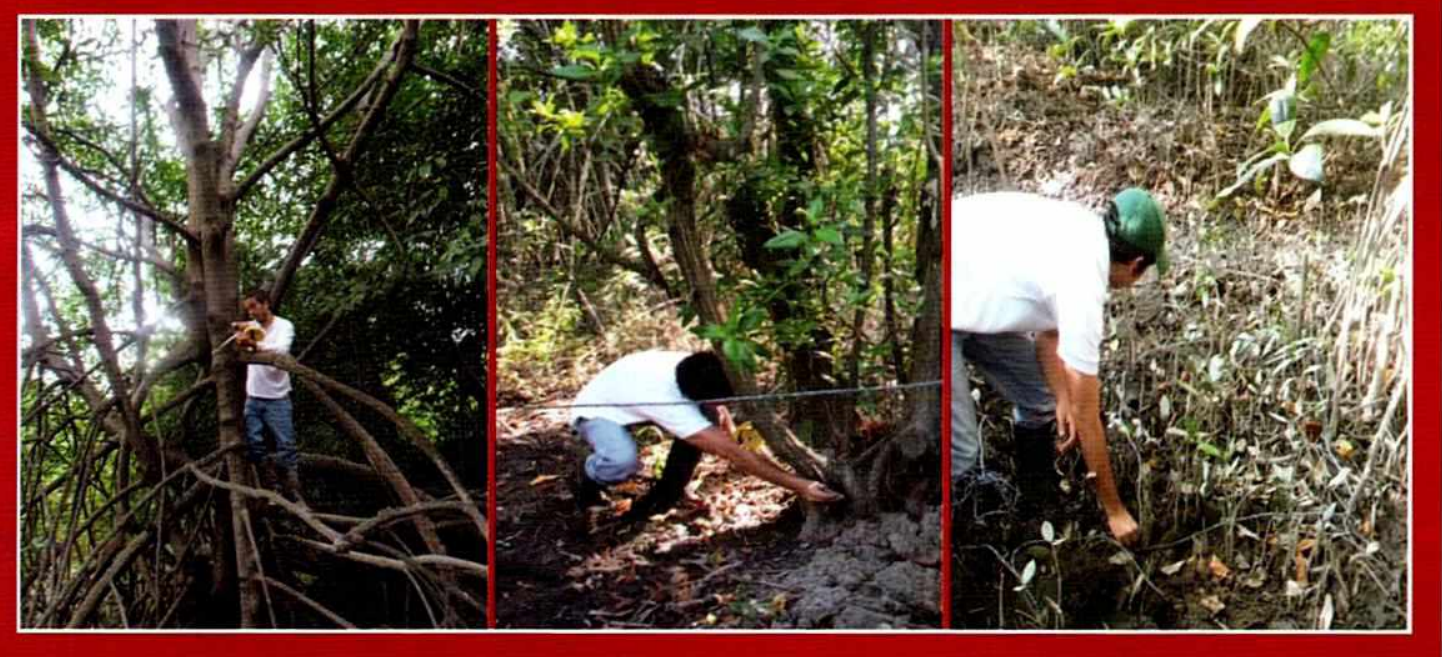


Para actualizar el inventario de todas las especies de mangle sembradas en el año 2000 se realizó el conteo de individuos de mangles de las cinco especies a través de transectos, en el cual se iban contabilizando las especies y detallando el área donde estaban ubicadas. Se utilizaron los senderos y los encierros de los animales como referencia para determinar el sitio de muestreo.

Para proponer nuevos lineamientos en el Plan de Manejo Ambiental (PMA) y mantener la estructura del manglar en el PHG se utilizó la metodología "propuesta por Gentry (1982) y discutida por Phillips \& Miller (2002), consiste en el levantamiento de vegetación en unidades de 0.1 ha, conformadas por 10 transectos de 2 x 50 metros" (Marcelo, Reynel, Zevallos, Bulnes y Pérez, 2007); sin embargo debido al espacio dentro del parque, el levantamiento de información se realizó en cuadrantes de $10 \times 10$ metros cada uno delimitados por cuerdas, luego se midió el Diámetro de Altura al Pecho (DAP), la altura y la copa de cada uno de los individuos encontrados dentro de la parcela que cumplían con el requisito de tener un diámetro mayor o igual a 2.5 centímetros a la altura del pecho, además se tomó en cuenta que los cuadrantes se localicen en áreas donde se planeó la zonación de las distintas especies de mangle.

En cada uno de los métodos utilizados se tomaron apuntes acerca de las observaciones que se detallarán en la sección de resultados y recomendaciones. Los cuadrantes fueron georeferenciados para conocer con mayor detalle los lugares de zonificación y realizar recomendaciones más puntuales para el plan de manejo del área de manglar del PHG.

Para proponer nuevos lineamientos al Plan de Manejo realizado por Molina Natalia, et al. 2006 se analizaron los programas, subprogramas y actividades establecidas y con los resultados obtenidos en los objetivos anteriores se plantea incluir algunas medidas que contribuirán a una mejor ejecución del plan de Manejo para mantener y conservar en buen estado el manglar del PHG.

\section{Resultados y Discusión}

Respecto a la actualización del inventario de los mangles del Género Rhizophora con placa originales del PHG, se analizaron las tablas e inventarios de los informes técnicos de los años 2000, 2002, 2005 y 2007 proporcionados por la Dirección del PHG, obteniendo los siguientes resultados que se muestran en la Figura 4: 296 individuos en el año 2000; 324 individuos en el 2002; 284 en el 2005; 237 individuos en el 2007 y en el 2014 se registraron 154 individuos. Según Molina Raquel, et al. (2000) solo el $40 \%$ de los individuos de Rhizophora se lograron identificar debido a su floración, siendo $R$. mangle $96 \%$ y $R$. harrisonii $4 \%$, en base a este diagnóstico se unificó el número total de 296 individuos de este Género. A partir del año 2002 se diferenciaron las especies de Rhizophora, siendo más abundante $R$. mangle hasta el año 2007 y en el 2014 se aprecia un considerable aumento de $R$. harrisonii, debido a que el muestreo se realizó en época de floración y se verificó que pertenecen a esa especie.

\section{Figura 4.}

Cantidad de individuos de género Rhizophora con placa en el PHG desde el año 2000 al 2014. Mendoza, X. 2014

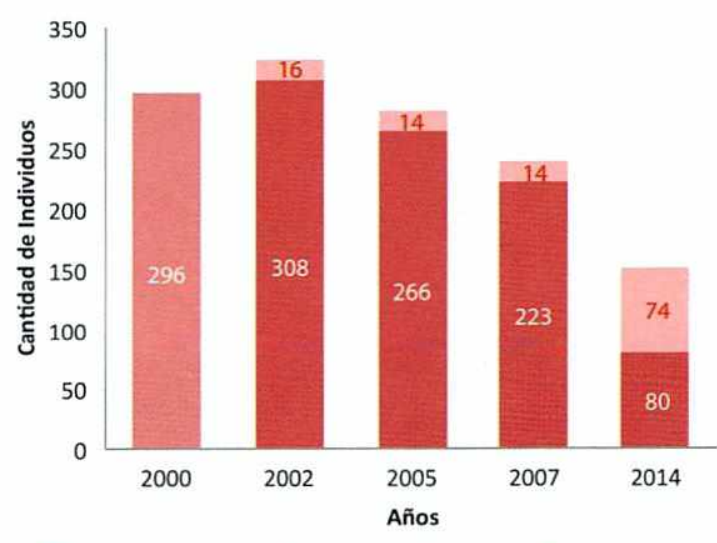

" Rhizophora mangle " Rhizophora harrisonii " "Rhizophora spp. 
Para estimar el DAP de los mangles se utilizaron 5 clases diamétricas en un rango desde $2.5 \mathrm{~cm}$ hasta $43.5 \mathrm{~cm}$., puesto que esta es la medida máxima encontrada, mientras que Molina, et al. (2000) utilizaron cuatro clases diamétricas para agrupar las medidas del DAP en un rango desde 2.5 hasta 36.5 $\mathrm{cm}$., siendo esta la medida máxima en ese año.
El número de individuos en cada rango se muestra en la Figura 5, es importante considerar que el número de individuos perdidos son 142, desde el año 2000 (296 individuos) al 2014 (154 individuos), aunque en este año se encontraron árboles con placa que no se registraron en el 2007, un factor que influye es la ubicación de la placa, que es difícil de encontrar.

\section{Figura 5.}

Comparación de rangos de DAP de Rhizophora spp. Mendoza, X. 2014

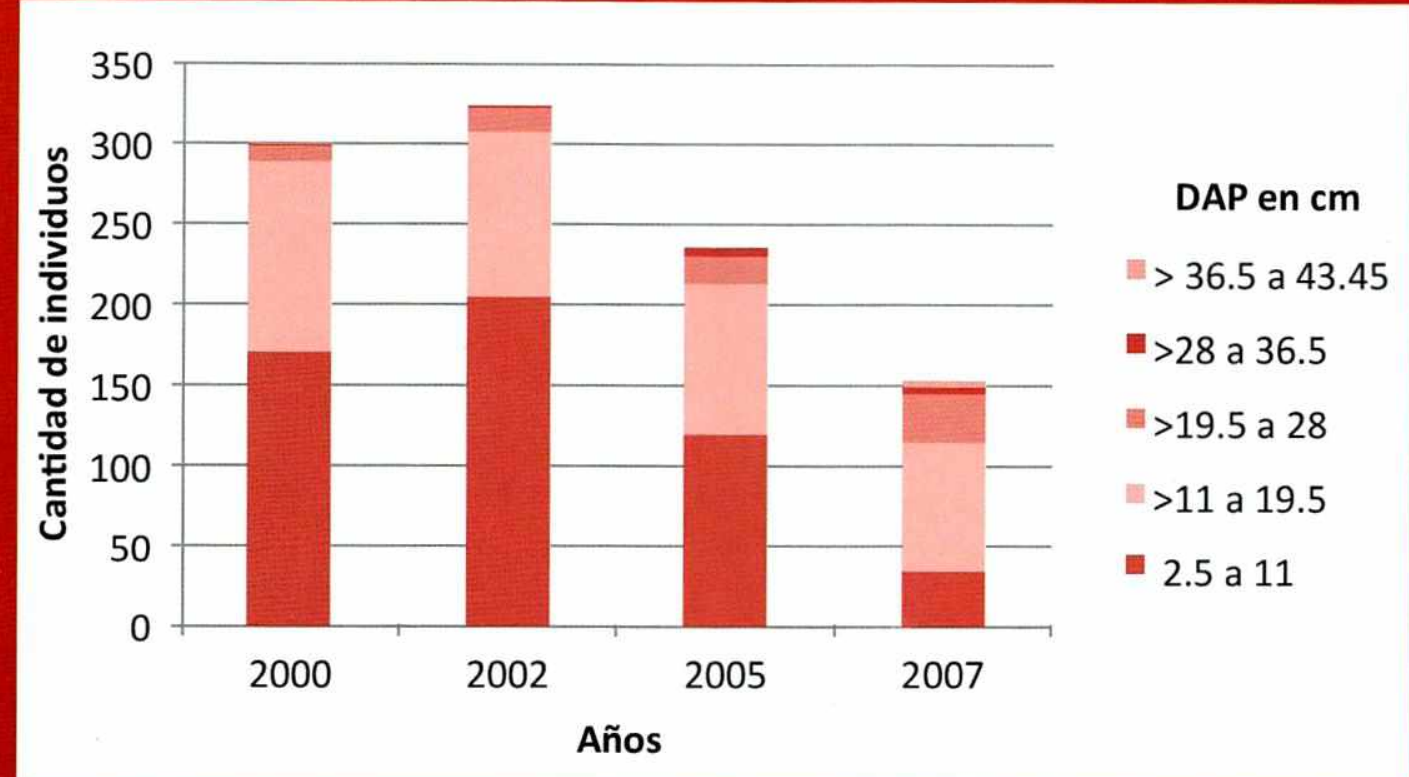

\section{Figura 6.}

Comparación del promedio de DAP de las especies Rhizophora mangle

y Rhizophora harrisonii. Mendoza, X. 2014

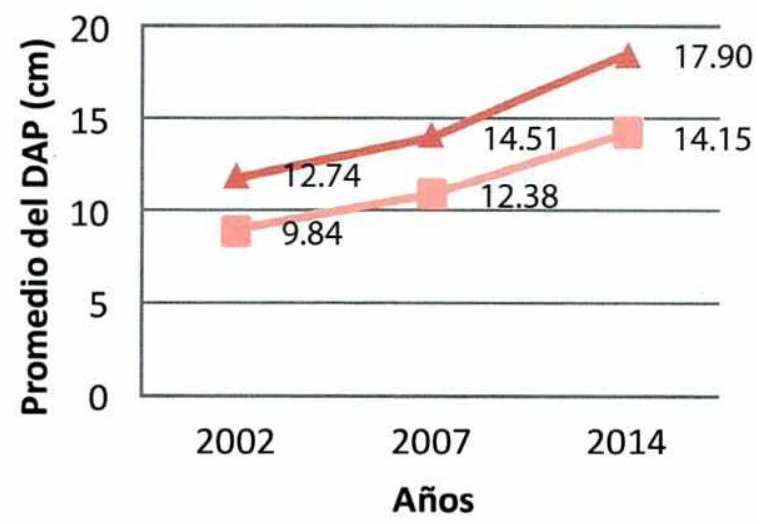

Promedio R. mangle

- Promedio $R$. harrisonii 
En la figura 6 se distinguen los promedios del DAP en los mangles que se encontraron con placa. $R$. mangle en el año 2002 presentó un promedio de $9.84 \mathrm{~cm}$ en el año $2007 ; 12.38 \mathrm{~cm}$ y el $2014 ; 14.15 \mathrm{~cm}$ lo que muestra un incremento de $4.31 \mathrm{~cm}$., cifra que se divide para los 12 años permite estimar un crecimiento de $0.36 \mathrm{~cm}$ por año.

$R$. harrisonii en el año 2002 presentó un promedio de $12.74 \mathrm{~cm}$; en el $2007 ; 14.51 \mathrm{~cm}$ y en el 2014; 17.90, lo que muestra un incremento de $5.16 \mathrm{~cm}$., estimando un crecimiento de $0.43 \mathrm{~cm}$ por año.

Según Boshier \& Cordero (2003), en El Salvador se midió el crecimiento en un manglar de 16 años de edad, el resultado del Incremento Medio Anual (IMA) fue de $0.85 \mathrm{~cm}$ de DAP y una densidad de 24 individuos por cada $100 \mathrm{~m} 2$.

Esta medida de IMA de $0.85 \mathrm{~cm}$ puede ser mayor, debido a que esos mangles son jóvenes y están en una etapa de crecimiento más rápida donde hay mayor competen- cia por la densidad, mientras que los mangles del PHG con IMA de $0.36 \mathrm{~cm}$ y $0.43 \mathrm{~cm}$ en $R$. mangle y $R$ harrisonii respectivamente, en su mayoría son árboles más viejos, por lo que también la densidad es más baja 15.5 individuos por cada $100 \mathrm{~m}^{2} \mathrm{y}$ considerando que este muestreo se realizó al azar donde están presentes otras especies de mangle, no solo las del Género Rhizophora.

En relación a la actualización del inventario de las especies de mangle sembradas desde el año 2000 hasta el 2005 se obtuvieron los siguientes resultados que se muestran en la Figura 7: Rhizophora spp 2,080 individuos (ind.) (78.6\%) en el año 2000, 3,842 ind., (54\%) en el año 2005 y 653 ind., (45.7\%) en el año 2014. A. germinans 134 ind., (5.1\%) en el año 2000; 1,520 ind., (21\%) en el año 2005 y 23 ind., (1.6\%) en el año 2014; L. racemosa 179 ind., (6.8\%) en el año 2000; 954 ind.,(13\%) en el 2005 y 44 ind., (3.1\%) en el 2014; C. erectus 250 ind.,(9.5\%) en el 2000; 831 ind.,(12\%) en el 2005 y 708 ind.,(49.6\%) en el 2014.

\section{Figura 7.}

Porcentaje de individuos por especie de mangles en el PHG desde el año 2000 al 2014. Mendoza, X. 2014

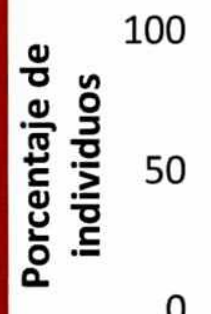

0

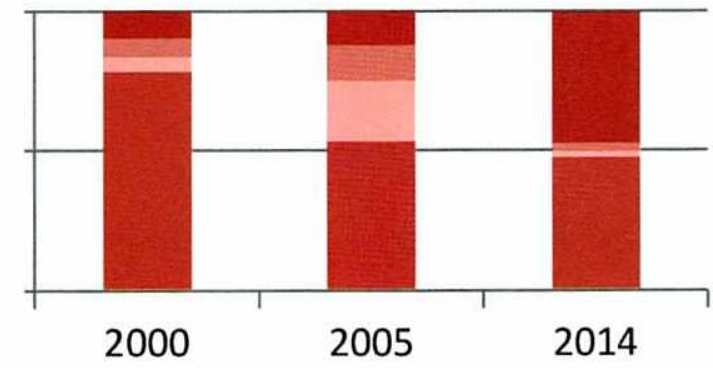

Años
Conocarpus erectus

- Laguncularia racemosa

Avicennia germinans

- Rhizophora SPP. 
Como se aprecia en la Figura 7 en el año 2014 la proporción que debía mantenerse de cada especie se ha alterado, L. racemosa y A. germinans son las especies más afectadas en su número de individuos. La reducción de estas especies es crítica ya que solo quedan 23 individuos de una siembra de 1520 A. germinans en el año 2005, una pérdida de 1497 individuos, que corresponde al $98.5 \%$ y 44 ind. de 954 L. racemosa sembrados el 2005, una pérdida de 910 individuos que equivale al $95.39 \%$. Se evidenció que esta pérdida se debe a la invasión de especies del Género Rhizophora que no es controlada, a la sedimentación por falta de dragado, a la falta de mantenimiento en cuanto a control de plagas, raleos, podas inadecuadas, y poco cuidado de la regeneración natural de estas dos especies. Estos datos reflejan la urgencia de recuperar la zonación establecida en el 2005 conservando la proporción del número de individuos en cada especie.

En cuanto a las especies del Género Rhizophora en el inventario 2014 se registraron 653 individuos de los cuales 311 son $R$. mangle y 342 son $R$. harrisonii, mientras que en el 2005 se registraron 3842 individuos de los cuales había 2991 R. mangle y $851 R$. harrisonii (Figura 8). Estas cifras evidencian que se ejecutó lo establecido en el PMA realizado por Molina, et al. (2006), donde indica que los mangles rojos deben ser raleados hasta lograr una distancia de 6 metros entre cada individuo, aunque la reducción es de 2680 en R. mangle y 509 en R. harrisonii aún no se ha logrado establecer la distancia recomendada entre todos los mangles rojos.

\section{Figura 8. \\ Comparación de la abundancia de $R$. mangle y $R$. harrisonii. Mendoza, X. 2014}

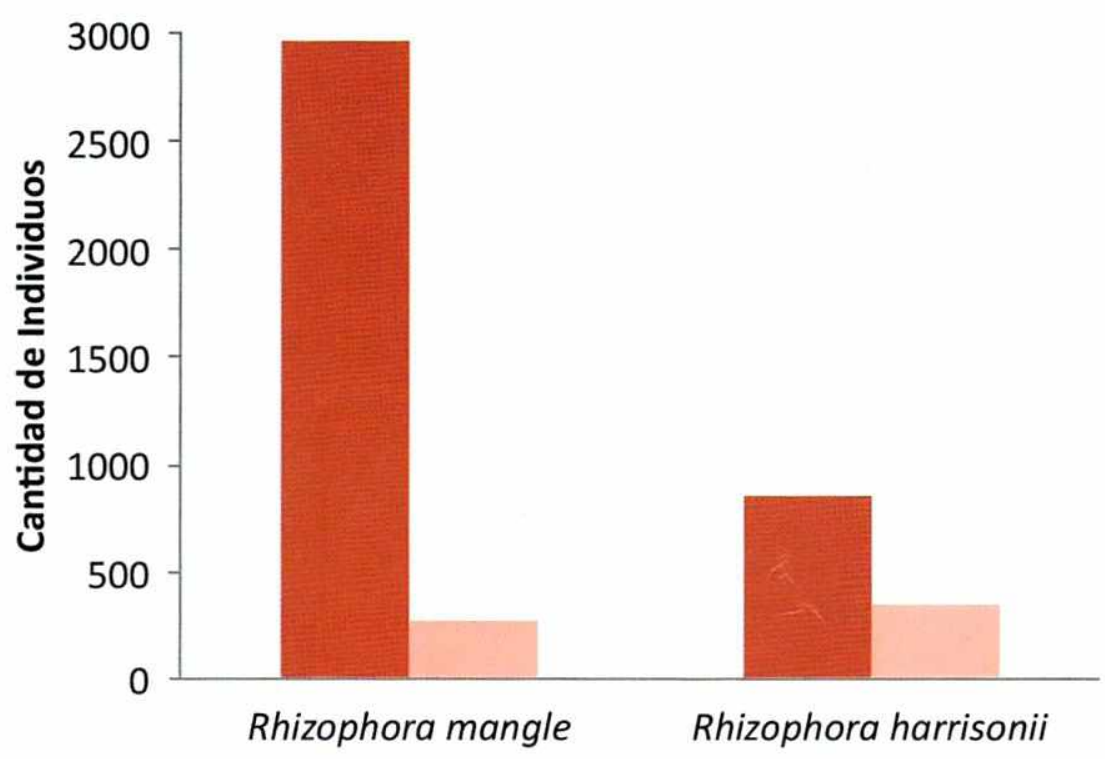

AÑO 2005

AÑO 2014

\section{Especies}


En cuanto a los nuevos lineamientos en el PMA para mantener la estructura del manglar en el PHG se obtuvieron los siguientes resultados: en cuanto a densidad en el 2014 se registraron 15.5 individuos por cada $100 \mathrm{~m} 2$; versus 8.96 individuos por cada $100 \mathrm{~m} 2$ según Molina, et al. (2000), además indica que el bosque estaba siendo afectado por plagas, y realizaron una comparación con otros mangles en estado saludable, como en Marfrisco, Reserva Ecológica Manglares Churute y Tres Bocas donde la densidad promedio fue de 23.1 individuos cada $100 \mathrm{~m}^{2}$.

Se debe considerar que esta densidad de 15.5 individuos por cada $100 \mathrm{~m} 2$ se obtuvo del muestreo realizado en 10 parcelas al azar, en las cuales estaban presentes las cinco especies de mangle, incluso hubieron parcelas con total dominancia de C. erectus, debido a que un área frente al Malecón 1900, es un bosque sólo de esta especie; mientras que Molina Raquel, et al. (2000) realizó el muestreo en parcelas con Rhizophora spp., que podían tener menos individuos, debido a la estructura de sus raíces fulcreas que abarca mayor espacio, debido a que en ese año solo habían esas especies en el PHG.
En el estudio realizado por Boshier \& Cordero (2003), se determinó una densidad de 24 árboles por cada $100 \mathrm{~m} 2$ en Barra de Santiago, El Salvador.

En cuanto a la regeneración natural (Figura 9) se realizó un muestreo con cuadrantes de $1 \mathrm{~m} 2$ para estimar la sobrevivencia de las plántulas del Género Rhizophora, obteniendo como resultado el $64 \%$ de mortalidad (30.3 individuos), $83 \%$ anclaje (39.5 individuos) y la sobrevivencia de los propágulos anclados es 14 individuos $/ \mathrm{m}^{2}$ versus los datos obtenidos por Molina Raquel, et al. (2000), que respecto a la mortalidad fue de $92 \%$, anclaje $83 \%$ y la sobrevivencia de los propágulos anclados es 0.56 individuos $/ \mathrm{m} 2$ afectados por el hongo Clodosporium y los comparó con la regeneración en otros manglares como Marfrisco, R. E. Manglares Churute y de Tres Bocas, los que superan el $70 \%$ de supervivencia, pero con 10.5, 0.3 y 2.7 individuos por $\mathrm{m}^{2}$.

Este resultado de sobrevivencia de 14 ind. por $\mathrm{m}^{2}$ supera los promedios encontrados por Molina Raquel, et al. (2000) en el PHG y en los manglares de otros lugares con los que comparó sus datos, lo que de-

\section{Figura 9.}

Regeneración de mangle en el PHG estimada en cuadrantes de $1 \mathrm{~m}^{2}$. Mendoza, X. 2014

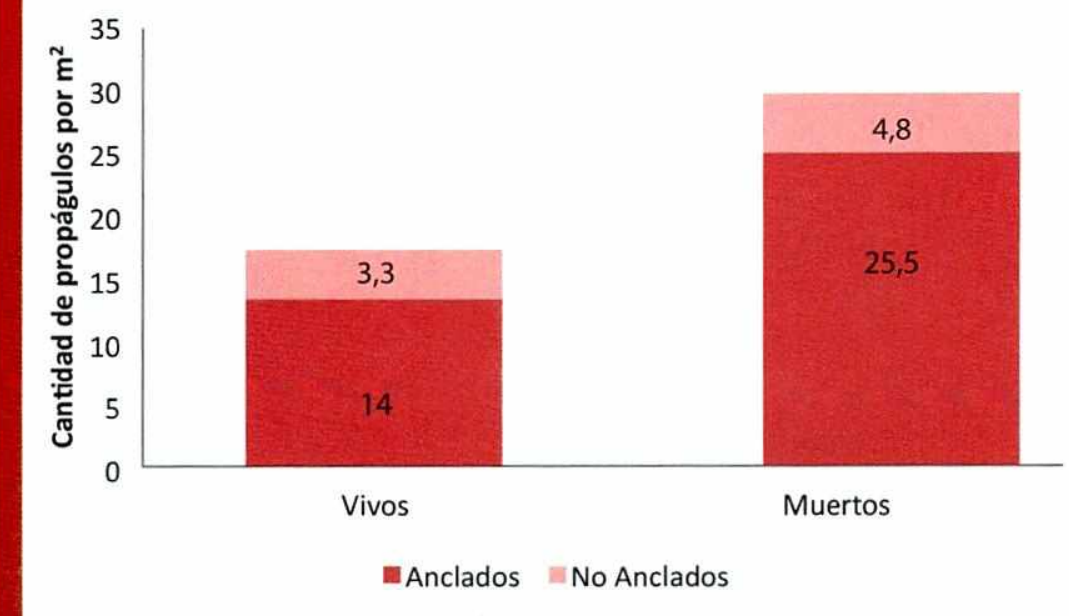

muestra que el trabajo de restauración del manglar que estos investigadores realizaron en el PHG ha sido exitoso, sin embargo es preocupante volver a encontrar propágulos afectados por la misma plaga Cocotripes sp. de la Familia Scolitidea del Orden Coleoptera que reportaron Molina, et al. (2000). 
En la figura 10 se observa el perfil del bosque de manglar dentro del PHG. Se identifican árboles de $R$. harrisonii que bordean los cuerpos de agua, llegando a alturas promedio de más de 8 metros, seguido por la especie $R$. mangle, con una disminución notable en la altura que llega a los 3 metros. A pesar de que el número de individuos de $A$. germinans y $L$. racemosa, es bajo alcanzan alturas promedio de 2.62 y 5 metros respectivamente.

Por último en las zonas en menor contacto con el agua se encuentra $C$. erectus con alturas promedio de 4.67 metros. Esta zonación debe mejorarse en cuanto al número de individuos de la especies $L$. racemosa y $A$. germinans para conservar la estructura vegetal del manglar que inició su restauración desde el año 2000.

\section{Figura 10.}

Perfil del bosque de manglar del PHG con las cinco especies: $R$. harrisonii $(1), R$. mangle (2), A. germinans (3), L. racemosa (4) y C.erectus (5). Mendoza, X. 2014

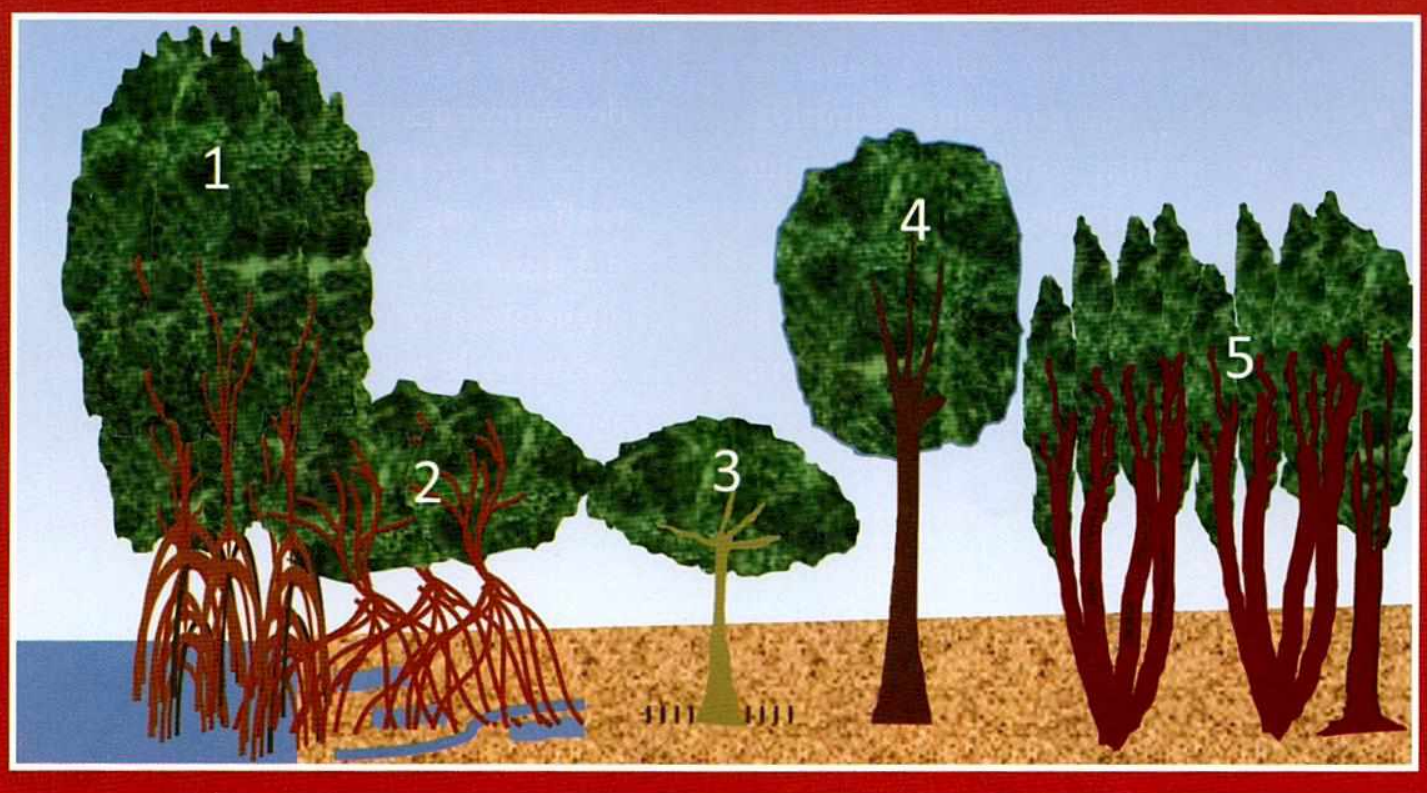

Molina, et al. (2006) elaboró un Plan de Manejo Ambiental (PMA) para cada tipo de bosque del PHG, mismo que consta de programas y subprogramas con objetivos y actividades bien detalladas para mantener el bosque de manglar, como la poda, alineamiento, raleo, reubicación de plantas, deshierba, limpieza de plantas, limpieza de canales, control de plagas, dragado y hacer nuevos canales.

$\mathrm{Si}$ se hubiesen ejecutado todas estas actividades de acuerdo al PMA, la zonación y el mantenimiento de cada especie se hubiese conservado y mejorado, sin embargo la zonación se ha alterado reduciendo significativamente el número de individuos de A. germinans y L. racemosa, además se evidencia malas prácticas de poda en $C$. erectus y falta de raleo en las especies del género Rhizophora, la sedimentación ha aumentado debido a la falta de dragado y conformación de canales necesarios para mantener el buen estado del bosque de manglar. Se propone incluir los siguientes lineamientos en el PMA:

1. Realizar un estricto control en la ejecución del PMA con informes ilustrados e indicadores que permitan auditar el cumplimiento de todas las actividades para recuperar y mantener la zonación del manglar en buen estado. 
2. Conformar pequeños viveros en sitio en los lugares donde hay regeneración natural de $A$. germinans y $L$. racemosa para asegurar un buen crecimiento $\mathrm{y}$ luego trasplantarlas a los lugares definitivos establecidos en el año 2005.

3. Georreferenciar los mangles originales del PHG y colocar nuevas placas u otro tipo de marcas que permitan continuar el estudio de crecimiento de estos mangles, e iniciar el estudio de crecimiento en los mangles establecidos a través de la restauración de este ecosistema. Es importante considerar que se debe continuar con el raleo; por lo cual es necesario determinar cuáles son los mangles que se van a quedar definitivamente, para evitar rotular mangles que luego deberán ser raleados.

4. Ejecutar auditorías internas y se recomienda realizar una auditoría externa, mínimo una vez al año.

5. Establecer la medición de manglares, llevando un registro de los individuos que mueren de manera natural y medir el crecimiento cada dos años, de preferencia en las mismas fechas.

6. Realizar muestreos de regeneración como un indicador del estado de los mangles.

7. Elaborar un diagnóstico de la presencia de plagas para evaluar el estado de la misma plaga que reportó Molina, et al. (2000), además si hay otras plagas diferentes y que tan significativa es su afectación para el desarrollo de los manglares.

8. Mantener personal especializado en el mantenimiento de manglar y capacitar al personal de otras áreas, para que en determinado momento puedan ayudar en las actividades del PMA.
9. Capacitación y actualización de los técnicos responsables del mantenimiento del bosque de manglar y de las áreas verdes del parque, ya que la zona de manglares limita con plantas ornamentales.

10. Se debe realizar un dragado anual durante la época de lluvia para facilitar la dilución de sedimentos, para esta actividad es necesario destinar un presupuesto para contratar personal que ejecute dicho trabajo. Actualmente no se observan raíces de $A$. germinans y $L$. racemosa debido a la fuerte sedimentación ocasionados por la falta de dragado. En el canal de ingreso el nivel de sedimentación es tan alto que está cerca del nivel de la caminera. De no realizar este dragado el manglar se debilitará y la presencia de plagas aumentará afectando la regeneración natural y la salud de todas las especies.

11. Establecer líneas de investigación de la fenología de los manglares y diversificar los temas de investigación para abarcar otros aspectos como la avifauna, entomofauna, ictiofauna, la repoblación de invertebrados como el cangrejo rojo (Ucides occidentalis) y otros grupos asociados a este ecosistema, además de fortalecer convenios con las universidades para mantener la investigación a largo plazo.

12. Fomentar las publicaciones de las investigaciones que se realicen en el PHG.

\section{Conclusiones}

Los resultados de la investigación determinaron una disminución del $52 \%$ de individuos en la cantidad total inventariada para el género Rhizophora, que fue rotulado con placa desde el año 2000 donde se registraron 296 individuos; en el 2014 se contabilizaron 154 individuos, hay tres causas que influyen en esta reducción, entre 
las que se incluye la muerte de varios árboles, la pérdida de placas porque se han caído o porque se han incrustado en los troncos y no se pueden leer, además de no haber encontrado las placas porque podrían estar ubicadas en lugares muy altos o poco visibles. Respecto a las medidas de crecimiento de DAP de los mangles del género Rhizophora debido al incremento de $7 \mathrm{~cm}$ en el valor máximo registrado $(43.5 \mathrm{~cm})$ se aumentó una clase diamétrica a las cuatro establecidas por Molina, et al. (2000) cuyo valor máximo registrado fue $36.5 \mathrm{~cm}$.

Al calcular el promedio del DAP, se obtuvo como resultado que la especie $R$. mangle tuvo un IMA de $0.36 \mathrm{~cm}$ por año, mientras que para $R$. harrisonii se estimó un IMA de $0.43 \mathrm{~cm}$. Estos datos junto a la densidad actual del bosque de manglar (15.5 individuos por cada $100 \mathrm{~m} 2$ ), al compararse con los valores de Boshier \& Cordero (2003) en el Salvador (0.85 IMA y 24 árboles $/ 100 \mathrm{~m} 2$ ) indican que las especies del Género Rhizophora en el PHG tienen un menor crecimiento que puede ser debido a su edad, y también al proceso de alta sedimentación a la que están expuestos estos manglares, ya que las del estudio de Boshier \& Cordero (2003) tuvieron que competir entre árboles recién reforestados y con una mayor densidad.

En cuanto a los árboles que fueron sembrados en el año 2005, es crítica la cantidad de L. racemosa y $A$. germinans, ya que disminuyen de 954 y 1520 individuos a 44 y 23 árboles respectivamente en el 2014, lo que se expresa como una pérdida de más del $95 \%$ de los individuos sembrados para cada especie. Se destaca la cantidad de $C$. erectus, (708 individuos) el cual mantiene una cantidad similar a la de la reforestación del 2005 (831 individuos), aunque no se menciona en el plan de manejo que esta especie debe ser raleada, hay una pérdida de 123 individuos, se ha evidenciado podas antitécnicas e inadecuadas en esta especie. El Género Rhizophora tiene una disminución que estaba proyectada en el Plan de Manejo de Molina, et al. (2006) y que aún no alcanza la distancia de $6 \mathrm{~m}$ entre cada individuo, por lo que se debe continuar el raleo.

La regeneración natural del PHG presentó promedios de 14 individuos anclados y vivos por cada $\mathrm{m}^{2}$, en cambio el valor del año 2000 fue de $0.56 \mathrm{ind} / \mathrm{m}^{2}$. Molina Raquel, et al. (2000) que compara ese valor con los de diferentes manglares, entre los cuales se encuentran Marfrisco (10.5 ind $/ \mathrm{m} 2)$, Tres Bocas $(2.7 \mathrm{ind} / \mathrm{m} 2)$ y la Reserva Churute $\left(0.3 \mathrm{ind} / \mathrm{m}^{2}\right)$, lo que indica que el PHG en el 2014 tiene una regeneración natural que supera las encontradas en los estudios mencionados; lo que evidencia que este ecosistema fue bien establecido por sus autores.

Sin embargo se debe realizar un seguimiento porque se encontraron plagas del género Cocotripes sp afectando la mayoría de propágulos (Figura 11).
Figura 11.

Propágulos afectados con plaga Cocotripes sp.

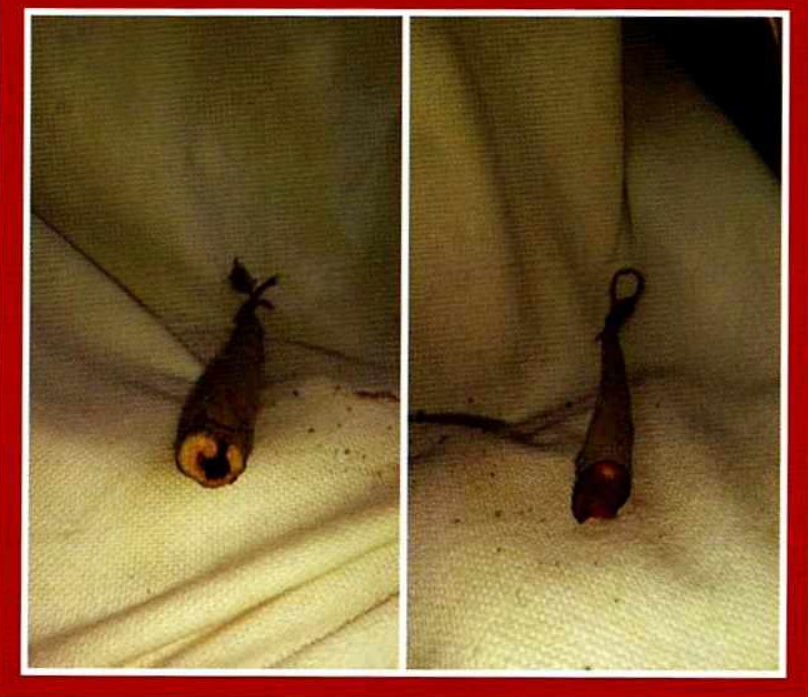


El PMA del PHG elaborado por Molina, et al. (2006) menciona actividades dentro de los programas y subprogramas que no se han ejecutado. Por lo tanto se evidencia que no se han ejecutado controles ni auditorias, por ejemplo la sedimentación se ha incrementado notablemente debido a la falta de dragado y buena conformación y mantenimiento de canales, la zonación de especies se ha alterado, no hay control de plagas, hay invasión de plantas ornamentales en el manglar, se encontraron varias podas antitécnicas e innecesarias en las que los árboles eran cortados a la mitad de su tronco (Figura 12).

\section{Figura 12. \\ Evidencia de un C. erectus (mangle jelí) podado en el PHG.}

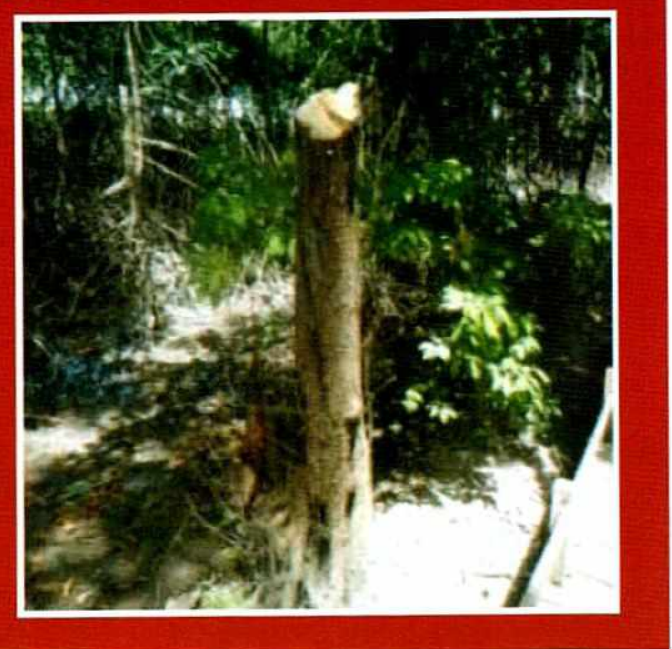

\section{Recomendaciones}

Se elaboraron las siguientes recomendaciones en base a los objetivos planteados y a las observaciones realizadas durante el trabajo de campo:

- Colocar nuevas placas que sean más visibles, para facilitar el trabajo a futuro y evitar que se sigan perdiendo datos, debido a que en ciertos mangles se caen las placas o se encuentran enterradas en el tronco.

- Realizar una georreferenciación de cada mangle con placa.

- En las áreas destinadas a bosque de manglar no se debe permitir el crecimiento de palmas (como es observado en la Figura 13) y cualquier otra especie que nazca de manera espontánea y que no pertenezcan al manglar, las que ya se encuentran deberán ser trasladadas a las áreas verdes donde se usan plantas ornamentales.

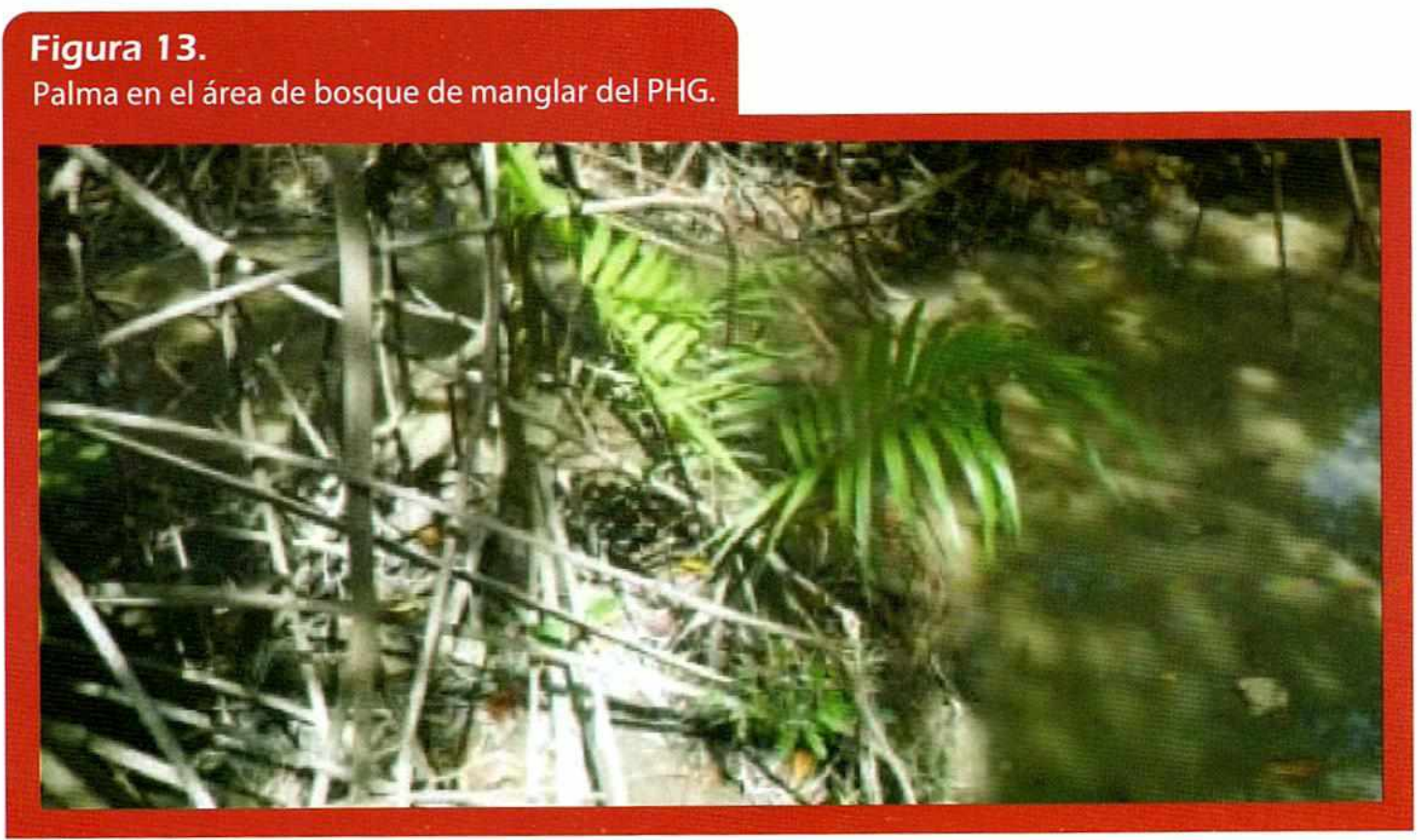


- Es importante mantener la zonación del bosque de manglar. En el área atrás de venados se debe controlar el crecimiento de Rhizophora spp. para que las demás especies no se vean afectadas, lo que se puede observar en los resultados del inventario, ya que el $L$. racemosa y $A$. germinans tienen una menor cantidad de individuos.

- Iniciar el estudio de crecimiento en los mangles sembrados a partir del año 2000 y rotularlos.

- Estudios como este deben realizarse periódicamente para medir el crecimiento y analizar el estado del bosque a través del tiempo.

- Es esencial el mantenimiento de los canales para un adecuado flujo deI agua y preservar esa característica del manglar; así como las zonas de inundación dentro del parque para evitar la sedimentación.

- Evaluar la presencia de plagas del bosque de manglar del PHG.

- Realizar estudios de suelo para medir los niveles de los sustratos y compararlos con los de un bosque de mangle en estado natural.

- Elaborar un estudio similar en los otros ecosistemas (bosque seco, bosque de garúa y llanura inundable) que se encuentran en el PHG.

- Evaluar la población de cangrejo rojo (Ucides occidentalis) que fue reintroducido en un número de 50 parejas en el año 2005.

\section{Bibliográfia}

Agraz, C., Noriega, R., López, J., Flores, F., y Jiménez, J. (2006). Guía de campo. Identificación de los manglares en México. Recuperado de: http://etzna.uacam.mx/epomex/pdf/Guia_Manglar.pdf

Bodero, A., Robadue, D. (1995). Estrategia para el Manejo del Ecosistema de Manglar, Ecuador. En Ochoa, M., editor. Manejo Costero Integrado en Ecuador. Fundación Pedro Vicente Maldonado. Guayaquil, Ecuador: Programa de Manejo de Recursos Costeros

Bolívar, J. (2014). Avances en la inclusión de los manglares y otros ecosistemas costeros en las estrategias de mitigación de cambio climático. Recuperado de:

http://www.carbonoybosques.org/images/stories/esp/Cambium/2014/ Vol-10-Nol.pdf

Boshier, D., y Cordero, J. (2003). Arboles de Centroamérica: Un manual para extensionistas. Recuperado de: http://books.google.com.ec/books? id=q-0NAQAAIAAJ $\& p g=P A 855 \& \mathrm{l} p g=P A 855 \& d q=$ manglar+crecimiento+por+ $\mathrm{a} \% \mathrm{C} 3 \% \mathrm{Bl}$ lo\&source $=\mathrm{bl} \& \mathrm{z}$ ts $=\mathrm{Esc} \_\mathrm{idkd}-$ $\mathrm{jC} \&$ sig $=\mathrm{B} 3 \mathrm{bIcv} 8 \mathrm{Mqla} 2 \mathrm{~g} 7 \mathrm{YYaD}$ IpV9E $1 \mathrm{Kuo} \& \mathrm{hl}=$ es\&sa $=\mathrm{X} \& \mathrm{ei}=\mathrm{I} 2 \mathrm{~A} 7 \mathrm{VL}$ 32AsPBggSZ5oIw\&ved =0CEAQ6AEw $\mathrm{Bg \# v}=$ onepage $\& \mathrm{q}=\mathrm{manglar} \% 20 \mathrm{crecimi}$ ento\%20por\%20a\%C3\%Blo\&f=false

Brown, L., Thein, A., Flavin, C., French, H., Jacobson, J., Low, M., Postel, S., y Renner, M. (1992). La situación en el mundo 1992. Buenos Aires: Sudamericana.

Cedeño, I., y Bravo, M. (2012). Protocolo de muestreo participativo: Capturas comerciales del cangrejo rojo de manglar (Ucides occidentalis) en el Golfo de Guayaquil. Guayaquil: Instituto Nacional de Pesca y USAID. 
Centro de Investigaciones Universitarias de la Universidad Laica Vicente Rocafuerte (1995). Ecología y desarrollo sustentable en Ecuador; "Los Manglares". Guayaquil: Universidad Laica Vicente Rocafuerte de Guayaquil.

Centro de Levantamientos Integrados de Recursos Naturales por Sensores Remotos. (2007). Actualización del estudio multitemporal de manglares, camaroneras y áreas salinas en la costa continental ecuatoriana. Ecuador: CLIRSEN

Cevallos, M., Cortez, M., y Hurtado, Y. (2010). Evaluación del uso recreativo y turístico del Refugio de Vida Silvestre Manglares El Morro. (Licenciatura en Turismo) Escuela Superior Politécnica del Litoral: Guayaquil, Ecuador. Recuperado de:

http://www.dspace.espol.edu.ec/handle/123456789/14547

Diaz, C., Castro, I., y Manjarrez, G. (2010). Mangles de Cartagena de Indias: "Patrimonio Biológico y fuente de Diversidad". Recuperado de: http://www.eumed.net libros-gratis/2010e/805/index.htm

Elite Consultor Cía. Ltda. (2013). Estudio de Impacto Ambiental "Proyecto edificio multipropósito Marriott plaza en sus fases de construcción, operación y mantenimiento de la parroquia la Puntilla, cantón Samborondón, provincia del Guayas". Recuperado de:

http://www.guayas.gob.ec/dmdocument $/ \mathrm{medio-a} \mathrm{mbiente/}$ eia/2013/2013-diciembre/EIA-MARRIOTT\%20PLAZA\%20Rev\%2005. pdf

Félix, E., Holguín, O., Hernández, A., y Flores, F. (2006). Producción primaria de los mangles del Estero El Conchalito en Bahia de La Paz (Baja California Su; México). Recuperado de: http://www.redalyc.org/articulo.oa? $\mathrm{id}=48032106$
Francisco, A., Díaz, M., Romano, M., y Sánchez, F. (2009). Descripción morfoanatomica de los tipos de glándulas foliares en el mangle blanco Laguncularia racemosa L. Gaertn (f.). Recuperado de:

http://web.b.ebscohost.com/ehost/pdfviewer/pdfviewer ? sid = 49d49c78-ccd4-4309-88d6-817d442bc9 dd\%40sessionmgr $114 \&$ vid $=7 \&$ hid $=$ 128

Infante, D., Moreno, P., y Madero C. (2014). ¿Pachira aquatica, un indicador del límite del manglar? En Revista Mexicana de Biodiversidad, 85: 143 160. Doi: $10.7550 / \mathrm{rmb} .32656$

Jiménez, J. (1999). Ambiente, distribución y características estructurales en los Manglares del Pacífico de Centro América: Contrastes climáticos, p. 51-70. Recuperado de: http://wwwl.inecol.edu.mx/ecosistemasdemanglar/Cap_6.pdf

Marcelo, J., Reynel, C., Zevallos, P., Bulnes, F., y Pérez, A, (2007). Diversidad, composición florística y endemismos en los bosques estacionalmente secos alterados del distrito de Jaén, Perú. Recuperado de: http://www.scielo.org.pe/scielo.php? script $=$ sci_arttext\&pid $=S 1726-22162007000100002$

Molina, R., Zambrano, R., Arias, M., y Vivas, M. (2000). Diagnóstico sobre la reforestación de manglar e identificación de insecto-plaga y enfermedades en el Parque Histórico Guayaquil. Guayaquil: Fundación Ecológica Rescate Jambelí.

Molina, R., y Molina, N. (2005). Proyecto zonificación del bosque de la zona de vida silvestre del Parque Histórico Guayaquil del Banco Central del Ecuador. Guayaquil: Fundación Ecológica Rescate Jambelí. 
Molina, N., Baquerizo, J., Orrantia, R., Fernández-Madrid, E., Pesántez, Y., y Pesántez, E. (2006). Informe final (2006) de los Programas de Bosques y Fauna de la Zona de Vida Silvestre del Parque Histórico Guayaquil para la Dirección de Cultura Regional de Guayaquil del Banco Central del Ecuador. Guayaquil: Fundación Ecológica Rescate Jambelí.

Moroyoqui, L., Flores, F., Hernández, G., Casas, M., Cervantes, R. y Nava, E. (2012). Remoción de nutrientes con dos especies de mangle (Rhizophora mangle y Laguncularia racemosa) en estanques experimentales de cultivo de camarón (Litopenaeus vannamei). Recuperado de:

http://www.scielo.org.mx/scielo. php? pid =S0185-38802012000300001\&s cript $=$ sci_arttext

Odum, E., y Sarmiento, F. (1997). Ecología: El puente entre ciencia y sociedad. México: McGraw-Hill Interamericana Editores S.A.

Olguín, J., Hernández, M., y Sánchez, G. (2007). Contaminación de manglares por hidrocarburos $y$ estrategias de biorremediación, fitorremediación $y$ restauración. Recuperado de: http:// scielo.unam.mx/scielo.php? pid $=\mathrm{S} 0188$ $49992007000300004 \&$ script $=$ sci_arttext \&tlng $=$ es

Parque Histórico Guayaquil. (2014). Recuperado de:

http://www.parquehistorico.gob. ec/web/index.ph p/2014-01-2315-46-58/hisoria

Parra, A., y Restrepo, J. (2014). El colapso ambiental en el río Patía, Colombia: variaciones morfológicas y alteraciones en los ecosistemas de manglar. 42: $40-$ 60. Doi: 103856/vol42-issuel-fulltext-4
Quintana, Y. (2007). Comparación de la Ictiofauna asociada a las raíces de mangle rojo (Rhizophora mangle: Rhizophoraceae), en los sitios Reserva Natural de Usos Múltiples Monterrico y Reserva Natural Privada Manchón Guamuchal, durante las épocas seca y lluviosa. (Bióloga) Universidad de San Carlos de Guatemala. Recuperado de: http://biblioteca.usac.edu.gt/tesis/06/06_2610.pdf

Reese, R. (2007). Restauración Ecológica de los manglares en la Costa del Ecuador. (Maestría en Ecología) Universidad San Francisco de Quito. Recuperado de: http://www.rncalliance.org/ WebRoot/rncalliance/Shops/rncalliance/4C12/F0C5/C677/9324/2525/C0 A8/D218/7C8F/Reese_Ronald.pdf

Sanjurio, E., y Welsh, S. (2005). Gaceta Ecológica \#74 "Una descripción del valor de los bienes y servicios ambientales prestados por los manglares". Recuperado de: http://www.redalyc.org/pdf/539/53907405.pdf

Smith, R. y Smith, T. (2001). Ecología, 4ta Edición. Madrid: Pearson Educación S.A.

Solano, F., Flores, L., y Ruíz, W. (2010). Captura de cangrejo rojo (Ucides occidentalis) en los puertos de la provincia del Guayas y El Oro, Ecuador, durante 2009. Guayaquil: Instituto Nacional de Pesca.

Suman, D. (1994). El ecosistema de manglar en América Latina y la cuenca del Caribe: Su manejo y conservación. Miami: University of Miami.

Universidad de Wisconsin (1975). El Hombre en el Medio Ambiente Vivo.

México: Continental S.A. 
Valverde, F.M., 1998. Plantas Útiles del Litoral Ecuatoriano. Ministerio de Medio Ambiente/ECORAE/EcoCiencia. Guayaquil. Pág. 19

Valverde, F.M., \& Pérez, J., (2012). La Biodiversidad Vegetal como Capital Natural de la Sostenibilidad en la Costa Ecuatoriana. Primera Edición, M. I. Municipalidad de Guayaquil. Pág. 61

Von Phral, H. (1987). Notas sobre la historia natural del mangle piñuelo Pelliciera rhizophorae (Theaceae) en el Pacífico colombiano, p. 117 - 122. Recuperado de:

http://matematicas.udea.edu.co/ actubiol/actualidadesbiologicas/ raba1986v15n58art2.pdf

Zamora, P. y Cortés, J. (2009). Los manglares de Costa Rica: El Pacífico norte. Recuperado de:

http://www.scielo.sa.cr/scielo.php? script $=$ sci_arttext $\&$ pid $=$ S 0034 77442009000300003

\section{Xavier Mendoza Delgado}

Ing. en Gestión Ambiental de la Universidad Espiritu Santo - Ecuador

E-mail:xmendoza@uees.edu.ec

\section{Natalia Molina Moreira}

Bióloga y Magister en Ciencias en Agricultura Tropical Sostenible

Docente tiempo completo de la Universidad Espiritu Santo - Ecuador

E-mail: natimolina@uees.edu.ec 